Journal of Applied Pharmaceutical Science Vol. 5 (04), pp. 058-064, April, 2015

Available online at http://www.japsonline.com

DOI: $10.7324 / \mathrm{JAPS} .2015 .50410$

ISSN 2231-3354 (cc) BY-NC-SA

\title{
Development of Enteric Coated Sustained Release Matrix Tablets of SertralineHydrochloride
}

\author{
Pravallika Uppala, Salma shaik, Saisri Anusha Valluru, Buchi N Nalluri* \\ Department of Pharmaceutics, KVSR Siddhartha College of Pharmaceutical Sciences, Vijayawada-520010, AP, India.
}

\begin{tabular}{|c|c|}
\hline ARTICLE INFO & ABSTRACT \\
\hline Article history: & \multirow{6}{*}{$\begin{array}{l}\text { The aim of the present investigation is to develop enteric coated sustained release matrix tablets of Sertraline } \\
\text { hydrochloride (STH) using HPMC K4M and Carbopol-971 as drug release retardants and cellulose acetate } \\
\text { phthalate (CAP) as an enteric coat polymer. The tablets were prepared by direct compression process and } \\
\text { evaluated for various physico-chemical/mechanical parameters. Among the two release retardants, HPMC K4M } \\
\text { was selected based on controlling the STH release during dissolution. The effect of different fillers like } \\
\text { microcrystalline cellulose (MCC), di calcium phosphate (DCP), spray dried lactose with maize starch (SDL) and } \\
\text { pre gelatinized starch (PGS), on STH release was also studied. The percent of STH released at the end of } \\
\text { dissolution with different fillers is in the order of SDL }>\mathrm{MCC}>\mathrm{DCP}>\mathrm{PGS} \text {. The tablets containing } 15 \% \mathrm{w} / \mathrm{w} \text { of } \\
\mathrm{HPMC} \text { K4M \& MCC as filler with } 5 \% \text { coating weight gain ( } 1 \% \text { v/v glycerine in } 5 \% \mathrm{w} / \mathrm{VAP} \text { solution) gave a } \\
\text { STH release of less than } 10 \% \text { in } 0.1 \mathrm{~N} \mathrm{HCl} \mathrm{(pH} 1.2) \text { for } 2 \mathrm{~h} \text { and a sustained release of STH over a period of } 12 \mathrm{~h} \\
(99.17 \pm 0.54 \%) \text { in pH } 6.8 \text { phosphate buffer and fulfilled the regulatory requirements. The dissolution data was } \\
\text { also evaluated for drug release kinetics and mechanisms. }\end{array}$} \\
\hline $11 / 2014$ & \\
\hline Revised on: & \\
\hline Accepted on: & \\
\hline Available online: $27 / 04 / 2015$ & \\
\hline $\begin{array}{l}\text { Key words: } \\
\text { enteric coated tablets, in vitro } \\
\text { drug release studies, } \\
\text { Sertraline hydrochloride, } \\
\text { sustained release }\end{array}$ & \\
\hline
\end{tabular}

\section{INTRODUCTION}

Sertraline hydrochloride (STH) is primarily selective serotonin reuptake inhibitor (SSRI) belongs to the class of antidepressant drug and anorectic agent categories. It is most commonly prescribed for the therapy of depressive illness in the dose range of $25-200 \mathrm{mg}$. Presently, STH is marketed as immediate release (IR) tablets $(25,50,100 \mathrm{mg})$ and oral concentrate $(20 \mathrm{mg} / \mathrm{mL})$. Severe side effects like nausea; regurgitation and diarrhea which are partially or primarily mediated by direct contact of STH with the upper GIT, preferably stomach were observed with higher doses (Am Ende, 2003). Hence, delivery of STH in a dosage form which minimizes the gastric exposure is necessary to reduce the dose related side effects in the upper GIT and release STH in the small intestinal region. STH when released in the small intestinal region may exhibit faster onset of action with shorter $\mathrm{T}_{\max }$ due to efficient absorption (Curatolo, 2003). Moreover, the sustained release (SR) in small intestine may

\footnotetext{
* Corresponding Author

Buchi N Nalluri, Department of Pharmaceutics, KVSR Siddhartha College of Pharmaceutical Sciences, Vijayawada-520010, AP, INDIA

Email: buchinalluri@yahoo.com
}

enhance the absorption of STH and results in improved therapeutic efficacy by shorter onset of action. So far, till to date no reports were published on STH enteric coated SR matrix tablets. Hence, the aim of the present study is to develop enteric coated SR matrix tablets of STH to achieve better therapeutic efficacy and more patient compliance when compared to marketed IR tablet dosage forms.

\section{MATERIALS AND METHODS}

\section{Materials}

Sertraline hydrochloride was obtained from Alekhya Laboratories, Vijayawada, India as a gift sample. Cellulose acetate phthalate was obtained from Sisco Research Laboratories Pvt.Ltd, Mumbai. HPMC K4M was obtained from Colorcon, India. Carbopol-971 was obtained from Lubrizol polymers, Belgium. Partially pre gelatinized starch, spray dried lactose with maize starch were obtained from Roquette Pharma, France. Dicalcium phosphate was obtained from Finar, Mumbai, India. Microcrystalline cellulose (Avicel PH 101) was obtained from FMC biopolymer, USA. Talc and magnesium stearate were obtained from Loba Chemie, India. All other reagents used were of analytical grade. 


\section{Solubility Studies of STH}

Buffers of $\mathrm{pH} 1.2$ acidic $(0.1 \mathrm{~N} \mathrm{HCl}), \mathrm{pH} 4.5$ acetate and pH 6.8 phosphate were used to study the solubility of STH. Excess of STH was added to $10 \mathrm{~mL}$ of buffer taken in a $15 \mathrm{~mL}$ stopper conical flask and shaken well for $24 \mathrm{~h}$ on a rotary flask shaker at room temperature. After $24 \mathrm{~h}$, samples were withdrawn and filtered through $0.45 \mu$ nylon disc filters. These filtrates were diluted suitably with buffer and measured at an absorbance of 213 nm (UV-VIS spectrophotometer, UV-1800-Shimadzu). The solubility studies were carried out in triplicate.

\section{Drug-Excipient Compatibility Studies} FTIR

The FT-IR spectra of STH and STH with different excipients like HPMC K4M, MCC, SDL, PGS, DCP, CAP, citric acid, magnesium stearate and talc was measured using ATR-FTIR spectrophotometer (Bruker, Germany). ATR spectra were measured over the wave number range of $4000-500 \mathrm{~cm}^{-1}$ at a resolution of $1.0 \mathrm{~cm}^{-1}$. The powder sample is simply placed onto the ATR crystal and the sample spectrum is collected.

\section{DSC}

Thermal analysis of pure STH and STH with selected excipients like HPMC K4M, MCC, DCP, SDL, PGS, magnesium stearate, talc and CAP was performed using DSC (DSC 200F3 Maia, Netzsch). The sample was sealed in a crimped aluminum pan by application of the minimum possible pressure and heated at a rate of $10{ }^{\circ} \mathrm{C} / \mathrm{min}$ from $30-300{ }^{\circ} \mathrm{C}$ in a nitrogen atmosphere. An empty aluminum pan was utilized as the reference pan.

\section{Preparation of STH SR Tablets by Direct Compression Technique}

STH SR Matrix tablets were prepared by direct compression method, as per the formulae given in Table 1. All the ingredients were passed through sieve \# 80 before mixing.
Initially drug and polymers were mixed thoroughly and then required quantities of fillers were added and then the blend was mixed with talc thoroughly for $5 \mathrm{~min}$ in a poly bag and then finally added the required amount of magnesium stearate and mixed for another $5 \mathrm{~min}$. Powder blends (for 50 tablets each) of all the formulations were compressed on single punch tablet press (Cad mach, India) using $10 \mathrm{~mm}$ punches (round shape) to a hardness of $4-6 \mathrm{~kg} / \mathrm{cm}^{2}$.

\section{Enteric Coating of SR Tablets}

The core tablets were coated with CAP by dip coating method and the coating solution formulae were given below. In dip coating method, the tablet cores were dipped into the coating solution in a beaker and then wet tablets were dried in a conventional manner by hot air blower. Coating was repeated until the target coat weight was achieved. $5 \%$ w/v CAP in Acetone: Methanol (50:50 v/v) solvent mixture was used for enteric coating of F3 SR matrix tablets using different plasticizers like Glycerine, PG and PEG-400 in coating solution (Table 2).

\section{$5 \%$ w/v of Cellulose Acetate Phthalate in Acetone}

Methanol (50:50) solvent mixture was prepared with addition of $1 \% \mathrm{v} / \mathrm{v}$ plasticizer (Glycerine or Propylene Glycol or Polyethylene Glycol). Precaution was taken always that CAP should be added to the solvent to make coating solution.

\section{Evaluation of Pre Compression Parameters of the Powder Blend}

Pre compression parameters like bulk density, tapped density, compressibility index, hausner's ratio and angle of repose of the prepared powder blend of all the formulations were studied.

\section{Evaluation of Post Compression Parameters of STH Tablets}

The compressed STH tablets were subjected to various physical tests which include hardness, friability, weight variation and drug content uniformity etc.

\begin{tabular}{|c|c|c|c|c|c|c|c|c|c|c|}
\hline $\begin{array}{l}\text { Ingredients } \\
(\mathrm{mg} / \mathrm{tab})\end{array}$ & F1 & F2 & F3 & F4 & F5 & F6 & F7 & F8 & F9 & F10 \\
\hline STH & 28 & 28 & 28 & 28 & 28 & 28 & 28 & 28 & 28 & 28 \\
\hline HPMC K4M & 20 & 24 & 30 & - & 10 & 30 & 30 & 30 & 30 & 30 \\
\hline CARBOPOL-971 & - & - & - & 30 & 20 & - & - & - & - & - \\
\hline $\mathrm{MCC}$ & 150 & 146 & 140 & 140 & 140 & 130 & 136 & - & - & - \\
\hline DCP & - & - & - & - & - & - & - & 140 & - & - \\
\hline SDL & - & - & - & - & - & - & - & - & 140 & - \\
\hline PGS & - & - & - & - & - & - & - & - & - & 140 \\
\hline Citric Acid & - & - & - & - & - & 10 & 4 & - & - & - \\
\hline MagnesiumStearate & 1 & 1 & 1 & 1 & 1 & 1 & 1 & 1 & 1 & 1 \\
\hline Talc & 1 & 1 & 1 & 1 & 1 & 1 & 1 & 1 & 1 & 1 \\
\hline Total weight (mg) & 200 & 200 & 200 & 200 & 200 & 200 & 200 & 200 & 200 & 200 \\
\hline
\end{tabular}

Table 2: Enteric coating solution formulations.

\begin{tabular}{|c|c|c|c|c|}
\hline \multirow{2}{*}{ Coating solution } & \multicolumn{4}{|c|}{ Formulations } \\
\hline & F11 & F12 & F13 & F14 \\
\hline CAP & $5 \% \mathrm{w} / \mathrm{v}$ & $5 \% \mathrm{w} / \mathrm{v}$ & $5 \% \mathrm{w} / \mathrm{v}$ & $5 \% \mathrm{w} / \mathrm{v}$ \\
\hline Acetone: Methanol & $50: 50 \mathrm{v} / \mathrm{v}$ & $50: 50 \mathrm{v} / \mathrm{v}$ & $50: 50 \mathrm{v} / \mathrm{v}$ & $50: 50 \mathrm{v} / \mathrm{v}$ \\
\hline Glycerine & $1 \% \mathrm{v} / \mathrm{v}$ & $1 \% \mathrm{v} / \mathrm{v}$ & - & - \\
\hline $1 \% \mathrm{PG}$ & - & - & $1 \% \mathrm{v} / \mathrm{v}$ & - \\
\hline $1 \%$ PEG & - & - & - & $1 \% \mathrm{v} / \mathrm{v}$ \\
\hline$\%$ Coat weight gain to the core & $10 \%$ & $5 \%$ & $5 \%$ & $5 \%$ \\
\hline
\end{tabular}




\section{Hardness}

The hardness of the tablets was measured with a Monsanto hardness tester (M/s Campbell Electronics, model EIC66 , India). The results reported were average of 6 tablets for each formulation.

\section{Friability}

For each formulation 10 tablets were weighed, placed in friabilator (M/S Campbell Electronics, India) and were subjected to 100 rotations in $4 \mathrm{~min}$. The tablets were reweighed and friability was calculated by the following formula:

$$
\text { Friability }=\frac{W_{2}-W_{1}}{W_{1}} \times 100
$$

Where $\mathrm{W}_{1}$ is the initial weight and $\mathrm{W}_{2}$ is the final weight of the tablets.

\section{Weight Variation}

The individual and total weight of 20 tablets from each batch was determined. Percentage deviation of the individual weights from the average weights was calculated.

\section{Drug Content}

Ten tablets were weighed individually; these were placed in a mortar and powdered with a pestle. Accurately weighed powder sample equivalent to $20 \mathrm{mg}$ of STH was transferred into a $20 \mathrm{ml}$ volumetric flask and made up to volume with $\mathrm{pH} 6.8$ phosphate buffer. The contents of the volumetric flask were sonicated for $15 \mathrm{~min}$ in-order to extract the drug into $\mathrm{pH} 6.8$ phosphate buffer. The solution was then filtered, suitably diluted with $\mathrm{pH} 6.8$ phosphate buffer and absorbance was measured at $213 \mathrm{~nm}$ using UV-VIS spectrophotometer (UV-1800-Shimadzu). The estimation was carried out in triplicate.

\section{In Vitro Drug Release Studies}

In vitro drug release studies of STH SR tablet formulations were carried in $900 \mathrm{~mL}$ of $\mathrm{pH} 6.8$ phosphate buffer as dissolution medium using USP type II (Paddle method) Dissolution Rate Test Apparatus (LABINDIA, DS 8000) at $50 \mathrm{rpm}$. Whereas, in case of enteric coated tablets, dissolution was carried out in $\mathrm{pH} 1.2$ acidic buffer $(0.1 \mathrm{~N} \mathrm{HCl})$ for initial $2 \mathrm{~h}$ and remaining time in $\mathrm{pH} 6.8$ phosphate buffer. The temperature was maintained constant at $37 \pm 0.5^{\circ} \mathrm{C}$.

At predetermined time intervals, $5 \mathrm{~mL}$ of sample was withdrawn from the dissolution medium and replacedwith equal volume of fresh medium. After filtration and appropriate dilution, the samples were analyzed at $213 \mathrm{~nm}$ for STH content against blank using UV-Visible spectrophotometer. The dissolution experiments were conducted in triplicate.

\section{Release Kinetics and Mechanism}

The release kinetics of the STH was studied by plotting the results of the in vitro drug release study with various kinetic models like Zero-order (cumulative percent drug release vs. time) (CS Brazel, 2000), First-order (log cumulative percent drug release vs. time) (Lapidus H, 1966), Higuchi's kinetics

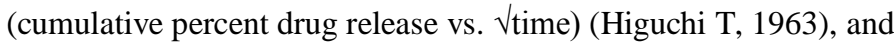
the Korsmeyer and Peppas equation (log cumulative percentage of drug release vs. log time) (Korsmeyer RW, 1983).

\section{RESULTS AND DISCUSSION}

\section{Solubility of STH in Different pH Buffers}

Solubility of STH in various $\mathrm{pH}$ buffers like $\mathrm{pH} 1.2$ acidic $(0.1 \mathrm{~N} \mathrm{HCl}), \mathrm{pH} 4.5$ acetate and $\mathrm{pH} 6.8$ phosphate was studied. This study was carried out with a view to select the suitable dissolution medium for STH.

The solubility of the STH in $\mathrm{pH} 4.5$ acetate buffer was found to be more when compared with $\mathrm{pH} 1.2$ and $\mathrm{pH} 6.8$ phosphate buffers (Figure 1). Even though, solubility of STH is less in $\mathrm{pH} 6.8$ phosphate buffer, when compared to the $\mathrm{pH} 1.2$ and 4.5 buffers, the $\mathrm{pH} 6.8$ phosphate buffer was selected as a dissolution medium based on the good solubility of enteric coat polymer CAP in $\mathrm{pH} 6.8$ phosphate buffer when compared to other buffers. Moreover, sink conditions can be maintained with $\mathrm{pH} 6.8$ phosphate buffer.

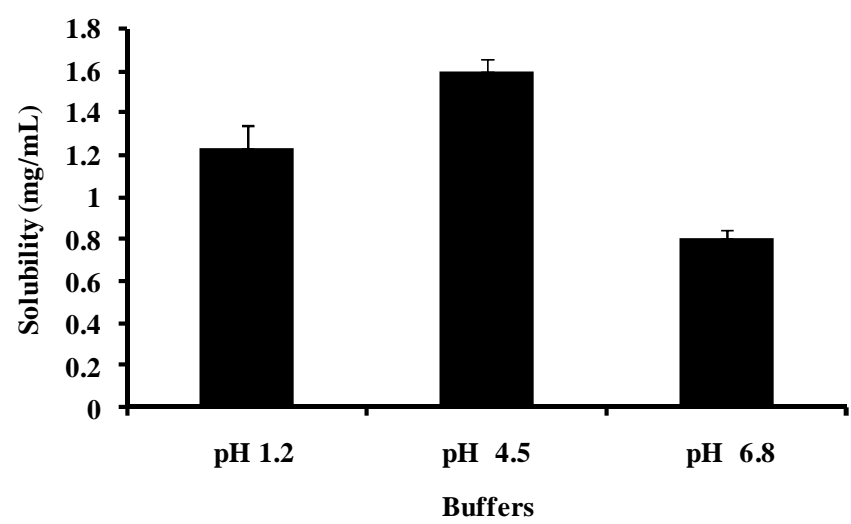

Fig. 1: Solubility of STH in various pH buffers.

\section{FTIR Studies}

FTIR spectroscopy was employed to find out the in situ compatibility of the STH with the selected excipients. Pure STH showed characteristic IR absorption bands at $902 \mathrm{~cm}^{-1}, 1211 \mathrm{~cm}^{-1}$, $1369 \mathrm{~cm}^{-1}, 1740 \mathrm{~cm}^{-1}, 2971 \mathrm{~cm}^{-1}$ and $3461 \mathrm{~cm}^{-1}$ of aromatic C-H group, C-N group, C-H alkane group, methyl bonded $\mathrm{NH}_{2}$ deformation, $\mathrm{C}-\mathrm{H}$ stretching of N-bonded $\mathrm{CH}_{2}$ group and $\mathrm{N}-\mathrm{H}$ group respectively.

These significant bands of STH were also present in the IR spectra of physical mixtures of STH with various excipients and thus, revealing the compatibility of STH with the selected excipients (Figure 2). 

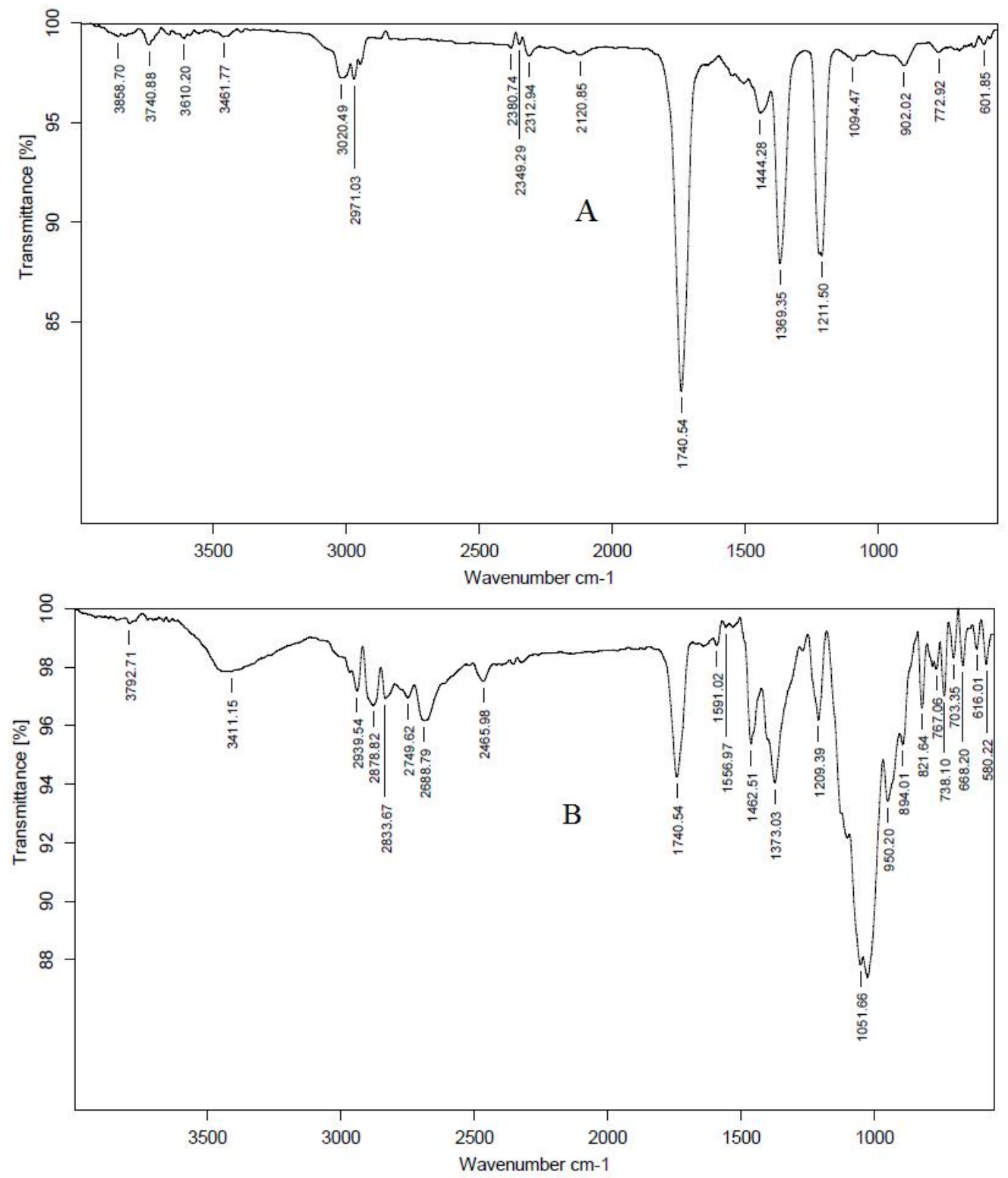

Fig. 2: FTIR spectra of STH (A) and F12 (B).

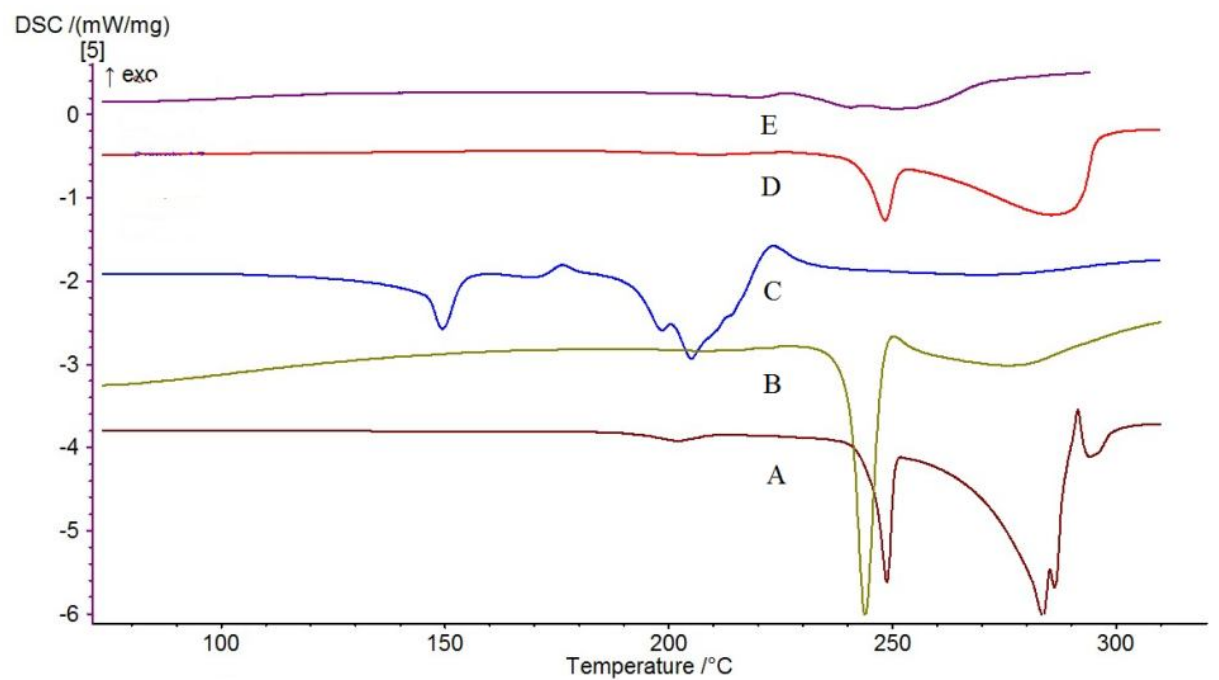

Fig. 3: DSC thermograms of STH (A), STH-PGS (B), STH-SDL (C), STH-DCP (D) and F12 (E). 


\section{DSC Studies}

DSC thermo grams of the STH alone and STH with the selected excipients were shown in Figure 3. The STH showed a sharp endothermic peak at around $248^{\circ} \mathrm{C}$ corresponding to its melting point. The sharp endothermic melting peak of STH at 248 ${ }^{\circ} \mathrm{C}$ was retained in all the thermo grams of STH with selected excipients and optimized formulation except with the SDL (peak shifted to lower melting point). In the case of SDL, the STH melting peak was shifted to $205^{\circ} \mathrm{C}$ and indicating a potential interaction of SDL with STH. Whereas, STH was compatible with all other excipients selected. However, in the case of optimized formulation, the STH peak intensity was reduced due to presence of less amount of STH.

\section{Determination of Pre and Post Compression Parameters}

The results of various pre compression parameters indicate that the powder blends of all formulations can be suitable to prepare tablets by direct compression technique. The compressed tablets fulfilled the official compendia requirements regarding drug content, uniformity of weight, hardness and friability.

\section{In Vitro Drug Release Studies}

\section{Effect of Release Retardant Concentration on STH release}

Initial formulation studies were carried out to look into the release retarding effect of HPMC K4M, at levels of $10-15 \%$ $\mathrm{w} / \mathrm{w}$ in the formulation using MCC as filler.

F1 containing 10\% w/w HPMC $\mathrm{K} 4 \mathrm{M}$ as a release retardant and MCC as filler gave a $65.87 \pm 0.64 \%$ initial burst release of STH at $1 \mathrm{~h}$ and $99.56 \pm 0.24 \%$ at the end of $4 \mathrm{~h}$. F2, containing $12 \% \mathrm{w} / \mathrm{w}$ HPMC K4M as a release retardant with MCC as filler gave $49.70 \pm 1.467 \%$ initial burst release of STH at $1 \mathrm{~h}$ and $99.71 \pm 0.236 \%$ at the end of $6 \mathrm{~h}$ and compared to F1 the STH release was extended to another $2 \mathrm{~h}$ i.e. for $6 \mathrm{~h}$. Concentration of HPMC K4M was further increased to $15 \% \mathrm{w} / \mathrm{w}$ with MCC as filler in $\mathrm{F} 3$, resulted initial burst release of $42.07 \pm 0.12 \%$ at $1 \mathrm{~h}$ and a complete release of STH i.e. $99.71 \pm 0.23 \%$ at the end of $10 \mathrm{~h}$. Comparative dissolution profile of F1, F2 and F3 was shown in Figure 4A.

Further trials were carried out using Carbopol-971 at a concentration of $15 \% \mathrm{w} / \mathrm{w}$ and $\mathrm{MCC}$ as filler with F4. A $63.76 \pm$ $0.83 \% \mathrm{STH}$ release of at the end of $12 \mathrm{~h}$ with an initial burst release of $9.59 \pm 0.11 \%$ at $1 \mathrm{~h}$. Whereas, in F5, instead of $15 \% \mathrm{w} / \mathrm{w}$ Carbopol-971, combination of Carbopol-971 and HPMC K4M at 10 and 5\% w/w respectively with $\mathrm{MCC}$ as a filler resulted an initial burst release of $3.73 \pm 0.12 \%$ and $19.31 \pm 1.04 \%$ at the end of $12 \mathrm{~h}$. The STH release from F5 is significantly lower when compared to F3 and F4 at the end of 12h. Comparative dissolution profile of F3 and F4 was shown in Figure 4B. Overall, addition of HMPC K4M didn't increase the STH release when compared to Carbopol-971 alone. Further trials were carried out using 15\% w/w of HPMC K4M as release retardant and MCC as filler.

F6 containing MCC as filler, 5\% w/w citric acid and 15\% w/w HPMC K4M as release retardant gave an initial burst release of $51.94 \pm 2.21 \%$ and a complete STH release of $99.14 \pm 0.48 \%$ at the end of $6 \mathrm{~h}$. Whereas, with F7 containing $2 \%$ w/w citric acid, an initial burst release of $45.39 \pm 1.68 \%$ and a complete release $(99.43 \pm 0.415 \%)$ at the end of $8 \mathrm{~h}$ was achieved. Comparative dissolution profile of F6 and F7 was shown in Figure 5. These results indicated that decrease in the citric acid levels showed lesser $\%$ of STH release from matrix tablets. This is because citric acid acts as an acidifying agent that may influences the micro environmental $\mathrm{pH}$ within the tablet core and increases the solubility of STH in intestinal fluids (Bolourchian, 2008). Even though, the F6 and F7 showed a good initial burst release and complete release of $\mathrm{STH}$, the reproducibility of hardness is troublesome in the presence of citric acid with different batches prepared. Hence, further trials were carried out with F3 to evaluate the effect of fillers on STH release from the SR tablets.
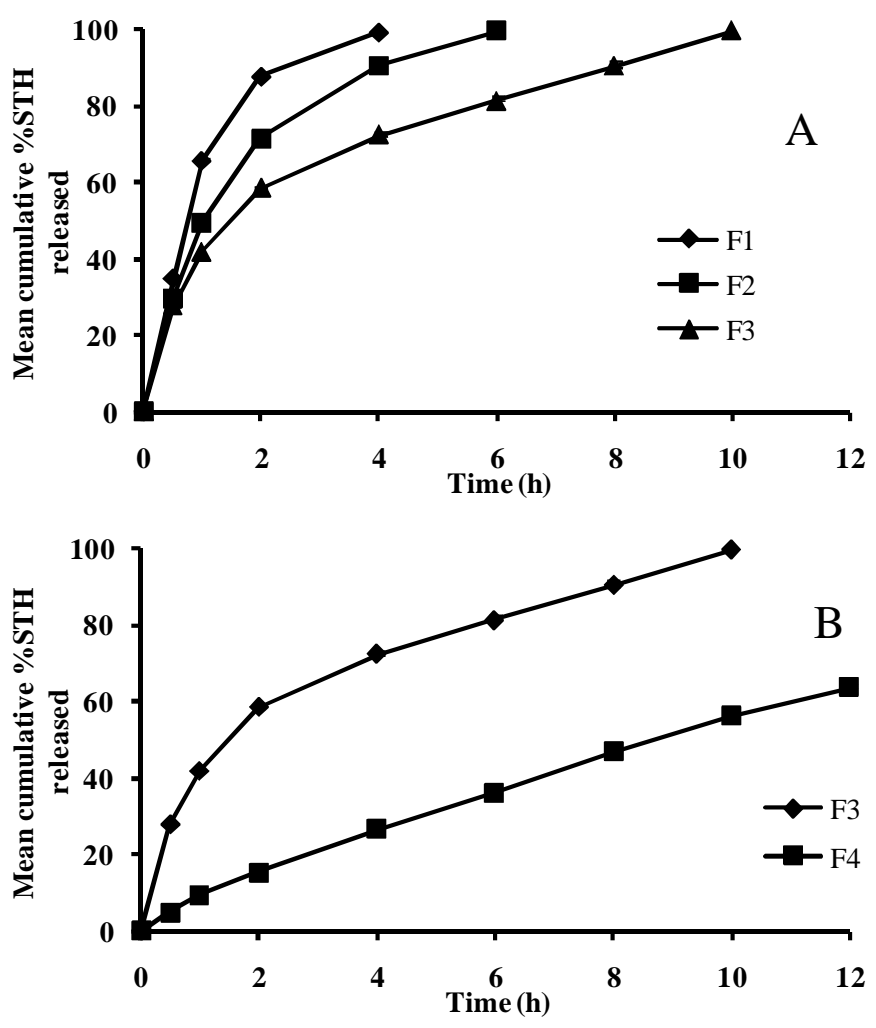

Fig 4: Comparative in vitro drug release profiles of STH (A) different concentrations of HPMC K4M (F1, F2 \& F3); (B) HPMC K4M (F3) and Carbopol-971 (F4)

\section{Effect of Fillers on STH Release from SR tablets}

All the formulations were prepared with $15 \% \mathrm{w} / \mathrm{w}$ HPMC K4M as a release retardant. F8 containing DCP as filler gave an initial burst release of $26.87 \pm 0.49 \% \mathrm{STH}$ at $1 \mathrm{~h}$ and a complete STH release i.e. $99.43 \pm 0.40 \%$ at the end of $10 \mathrm{~h}$. This is due to lower swelling capacity of DCP when compared to MCC.

F9 containing SDL as filler gave an initial burst release of $43.16 \pm 0.41 \% \mathrm{STH}$ at $1 \mathrm{~h}$ and a complete release i.e. $99.42 \pm$ $0.42 \%$ at the end of $6 \mathrm{~h}$ and the tablets were completely dissolved. This could be due to water soluble nature of SDL and thereby 
making the channels in gel matrix. However, SDL was not preferred in further developmental studies; since the STH is incompatible with SDL. F10 containing PGS as filler gave an initial burst release of $10.50 \pm 0.19 \% \mathrm{STH}$ at $1 \mathrm{~h}$ and $68.53 \pm$ $0.635 \%$ at the end of $12 \mathrm{~h}$ and is may be due to the insoluble nature and lower swelling capacity of PGS. The tablets were intact and gel layer remained even at the end of $12 \mathrm{~h}$.

Overall, the initial burst release of STH at $1 \mathrm{~h}$ was in the order of SDL > MCC > DCP > PGS with 15\% w/w HPMC K4M as a release retardant. F8 containing DCP as filler showed complete STH release within $10 \mathrm{~h}$ as like F3, however, the initial burst release observed with the F3 was higher i.e. $42.07 \pm 0.12 \%$ when compared to $\mathrm{F} 8$ i.e. $26.87 \pm 0.49 \%$. The release retarding effect of $15 \% \mathrm{w} / \mathrm{w}$ HPMC K4M in the presence of different fillers is in the order of PGS $>\mathrm{DCP}>\mathrm{MCC}>\mathrm{SDL}$. Comparative dissolution profile of F3, F8, F9 and F10 was shown in Figure 6 A.

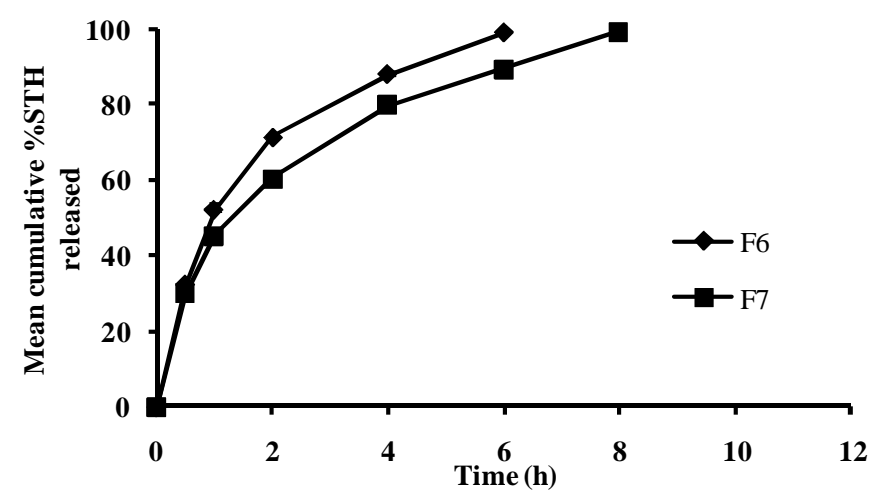

Fig. 5: Comparative in vitro drug release profiles of STH with different concentrations of citric acid- F6 (5\%w/w) and F7 (2\%w/w)

Overall, the formulation F3 containing 15\% w/w HPMC $\mathrm{K} 4 \mathrm{M}$ as a release retardant with $\mathrm{MCC}$ as filler gave complete STH release at the end of $10 \mathrm{~h}$ in a sustained release manner with an initial burst release of $42.07 \pm 0.12 \%$. Based on these results, F3 was selected for enteric coating trials. In vitro release studies of F3 were also carried out only in $\mathrm{pH} 1.2$ acidic buffer $(0.1 \mathrm{~N} \mathrm{HCl})$ up to $12 \mathrm{~h}\left(\mathrm{~F}^{*}\right)$ and also in $\mathrm{pH} 1.2$ acidic buffer $(0.1 \mathrm{~N} \mathrm{HCl})$ for initial $2 \mathrm{~h}$ and up to $10 \mathrm{~h}$ in $\mathrm{pH} 6.8$ phosphate buffer (F3**) for comparison. $\mathrm{F}^{*}$ gave an initial burst release of $46.59 \pm 1.18 \%$ and a complete STH release within $8 \mathrm{~h}(99.03 \pm 0.68 \%)$. Whereas, F3** gave an initial burst release of $62.14 \pm 1.03 \%$ at $2 \mathrm{~h}$ and $99.28 \pm 0.70 \%$ at the end $10 \mathrm{~h}$. From the above dissolution data, F3 was further selected for enteric coating trials with cellulose acetate phthalate (CAP) in order to achieve less than $10 \%$ STH release, in the stomach region and complete release in the intestinal region.

\section{Effect of Plasticizers in Enteric Coating Solution on STH Release from Coated SR Tablets}

$5 \% \mathrm{w} / \mathrm{v}$ CAP solution with $1 \% \mathrm{v} / \mathrm{v}$ Glycerine as plasticizer was tried initially (F11) with a $10 \%$ coating weight gain and gave a STH release of $6.05 \pm 0.16 \%$ in $\mathrm{pH} 1.2$ acidic buffer
$(0.1 \mathrm{~N} \mathrm{HCl})$ at $2 \mathrm{~h}$ and $80.28 \pm 0.15 \%$ at the end of $10 \mathrm{~h}$ in $\mathrm{pH} 6.8$ phosphate buffer. Whereas, F12 with a $5 \%$ coating weight gain gave a STH release of $9.44 \pm 0.16 \%$ at $2 \mathrm{~h}$ in $\mathrm{pH} 1.2$ acidic buffer $(0.1 \mathrm{~N} \mathrm{HCl})$ and $99.17 \pm 0.54 \%$ at the end of $10 \mathrm{~h}$ in $\mathrm{pH} 6.8$ phosphate buffer. The superior dissolution profile observed with the F12 is may be because of low thickness of the enteric coating layer on SR tablets and further trials were carried out with $5 \%$ weight gain of the coating solution.

Further trials were carried out by replacing the plasticizer with PG in order to evaluate the affect on STH release. F13 with $1 \% \mathrm{v} / \mathrm{v} \mathrm{PG}$ as plasticizer in coating solution gave a STH release of $18.20 \pm 0.65 \%$ in $\mathrm{pH} 1.2$ acidic buffer $(0.1 \mathrm{~N} \mathrm{HCl})$ at $2 \mathrm{~h}$ and 99.55 $\pm 0.32 \%$ at the end of $10 \mathrm{~h}$ in $\mathrm{pH} 6.8$ phosphate buffer. Higher $\%$ of $\mathrm{STH}$ released in $\mathrm{pH} 1.2$ acidic buffer $(0.1 \mathrm{~N} \mathrm{HCl})$ for initial $2 \mathrm{~h}$ was due to less viscosity nature coating solution when PG was added when compared to glycerine and not fulfilled the compendial requirement for enteric coated tablets i.e. less than $10 \%$ in $2 \mathrm{~h}$ in $\mathrm{pH} 1.2$ acidic buffer $(0.1 \mathrm{~N} \mathrm{HCl})$.
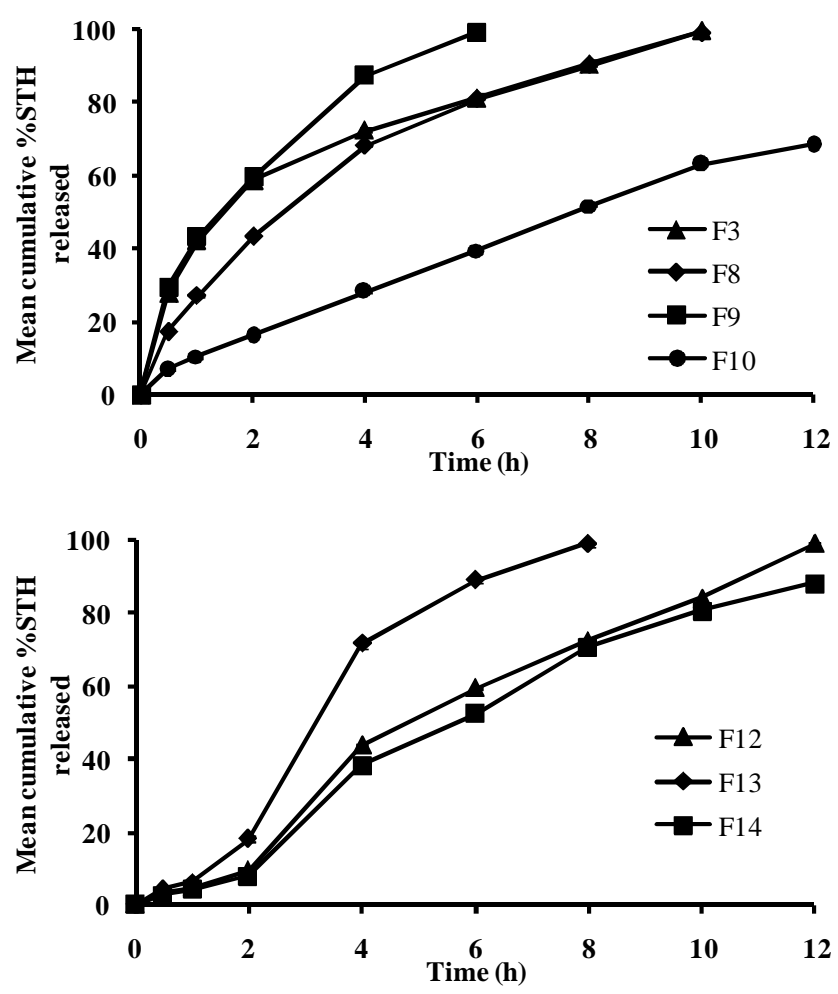

Fig. 6: Comparative in vitro drug release profiles of STH using different fillers (A) and enteric coated tablets with different pasticizers- F3 (MCC), F8 (DCP), F9 (SDL) and F10 (PGS), F12 (Glycerine), F13 (PG) and F14 (PEG-400)

Whereas, F14 with 1\%v/v PEG-400 as plasticizer gave a STH release of $7.97 \pm 0.22 \%$ in $\mathrm{pH} 1.2$ acidic buffer $(0.1 \mathrm{~N} \mathrm{HCl})$ at $2 \mathrm{~h}$ and $88.50 \pm 0.56 \%$ at the end of $10 \mathrm{~h}$ in $\mathrm{pH} 6.8$ phosphate buffer. The lower STH release at the end of $12 \mathrm{~h}$ is may be because of the high viscous nature of PEG when compared to the glycerine and PG. Comparative dissoltion profiles of F12, F13 and F14 were shown in Figure 6 B. Overall, F12 (enteric coated formulation containing Glycerine as a plasticizer with $5 \%$ coating 
weight gain) gave STH release $<10 \%$ in $\mathrm{pH} 1.2$ acidic buffer $(0.1 \mathrm{~N} \mathrm{HCl})$ and complete release of STH within $12 \mathrm{~h}$ and has fulfilled the regulatory requirements in terms of percent drug release (i.e. not less than $85 \%$ at the end of dissolution studies i.e., $12 \mathrm{~h}$ ) and also fulfilled the compendial requirement for enteric coated tablets i.e. less than $10 \%$ in $2 \mathrm{~h}$ in $\mathrm{pH} 1.2$ acidic buffer.

\section{Drug Release Kinetics and Mechanism}

The $\mathrm{R}^{2}$ values for F1-F10 obtained with first order plots were found to be superior when compared to the $\mathrm{R}^{2}$ values obtained with zero order plots. These results indicated that the STH release from F1-F10 followed first order kinetics. The Higuchi square root model showed higher correlation coefficient values (0.894-0.996) and diffusion is the release mechanism for STH from tablets. The graphs of Log $Q_{t} / Q$ versus $\log t$ showed a linear relationship with $\mathrm{R}^{2}$ values ranged from $0.993-1$ and ' $\mathrm{n}$ ' values from $0.463-0.772$. The formulations showed values of $n$ $>0.45$ but $<0.89$, indicating anomalous transport as the release mechanism which includes both swelling and erosion.

\section{CONCLUSION}

From the results obtained, it can be concluded that enteric coated sustained release matrix tablets of STH can be successfully formulated using HPMC K4M as release retardant and MCC as filler (F3) with an enteric coat CAP formulation containing glycerine as a plasticizer with $5 \%$ coating weight gain. This formulation may minimizes the side effect profile observed with higher doses and also to achieve faster onset of action for better patient compliance when compared to existing marketed dosage forms i.e., immediate release tablets.

\section{ACKNOWLEDGEMENTS}

The authors are thankful to the Alekhya Laboratories for providing Sertraline Hydrochloride sample and Siddhartha Academy of General and Technical Education, Vijayawada, for providing necessary facilities to carry out this research work.

\section{REFERENCES}

Am Ende MT, Curatolo WJ. Sertraline salts and sustain release dosage forms of Sertraline. US patent 6517866, 2003.

Bolourchian N, Dadashzadeh S. pH-independent release of propranolol hydrochloride from HPMC based matrices using organic acids. DARU J Pharm Sci, 2008;16: 136-142.

Brazel CS, Peppas NA. Modeling of drug release from swellable polymers. European Journal of Pharmaceutics and Biopharmaceutics, 2000; 49: 47-58.

Curatolo WJ, Friedman HL. Delayed Release Dosage Forms of Sertraline. European Patent 1007024B1, 2003.

Higuchi T. Mechanism of sustained action medication, theoretical analysis of rate of release solid drugs dispersed in solid matrices. Journal of Pharmaceutical Sciences, 1963;52:1145-1148.

Korsmeyer RW, Gurny R, Doelker E, Buri P, and Peppas NA. Mechanism of solute release from porous hydrophilic polymers. International Journal of Pharmaceutics, 1983; 15: 25-35.

Lapidus H, Lordi NG. Drug release from compressed hydrophilic matrices. Journal of Pharmaceutical Sciences, 1966;55:840843.

\section{How to cite this article:}

Uppala P., Shaik S., Anusha Valluru S., Nalluri B. N. Development of Enteric Coated Sustained Release Matrix Tablets of Sertraline Hydrochloride. J App Pharm Sci, 2015; 5 (04): 058-064. 